\title{
Educação em Saúde na atenção médica ao paciente com hipertensão arterial no Programa Saúde da Família*
}

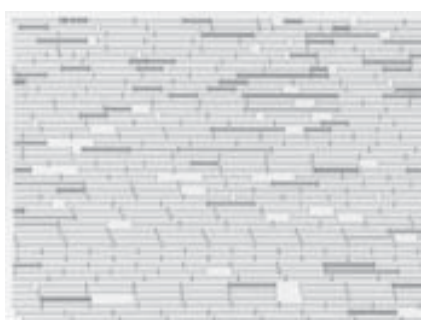

Vânia Sampaio Alves ${ }^{1}$

Mônica de Oliveira Nunes²

ALVES, V. S.; NUNES, M. O. Health education in connection with medical attention to hypertensive patients in the family health program. Interface - Comunic., Saúde, Educ., v.10, n.19, p.131-47, jan/jun 2006.

Of the many contexts in which health education actions are conducted, the present work focused on medical consultations. Aiming to identify and characterize these actions within medical attention, the transcripts of fifty consultations with hypertensive patients, conducted by ten family health physicians in three municipalities of the State of Bahia, were analyzed. The results show that consultations are conducted in a way that emphasizes both medicalization and hypertension control. The patient's narrative is inhibited or interrupted by the physician's narrative, medical attention remaining restricted to individual symptoms, with no grasp of the psycho-social and cultural dimensions of the health-illness-care process. In most of the consultations, the educational action is secondary and superficial, leading to prescriptive recommendations. However, one of the physicians appeared to have a different approach, which points to the possibility of a type of medical attention based on dialogue and on integrating biomedical and sociocultural aspects into healthcare.

KEY WORDS: health education. healer-patient relationship. family health program. hypertension.

Entre os muitos contextos de desenvolvimento da ação educativa em saúde, o presente trabalho privilegiou a consulta médica. Com o objetivo de identificar e caracterizar essas ações na atenção médica, analisaram-se as transcrições de cinqüenta consultas com pacientes hipertensos, realizadas por dez médicos de Saúde da Família em três municípios baianos. Os resultados demonstram que a condução da consulta enfatiza a medicalização e o controle da hipertensão. A narrativa do paciente é inibida ou interrompida pela narrativa do médico, com a atenção médica circunscrevendo-se aos sintomas individuais, sem apreensão das dimensões psicossociais e culturais do processo saúde-doença-cuidado. A ação educativa, na maior parte dessas consultas, apresenta-se secundária e superficial, com recomendações prescritivas. Uma abordagem diferenciada foi identificada entre um dos médicos, apontando para a possibilidade de uma atenção médica dialógica e integradora de aspectos biomédicos e socioculturais ao cuidado.

PALAVRAS-CHAVE: educação em saúde. relação médico-paciente. programa saúde da família. hipertensão.

*Elaborado a partir de Alves (2004).

${ }^{1}$ Professora substituta, departamento de Saúde Coletiva I, I nstituto de Saúde Coletiva, Universidade Federal da Bahia (ISC/UFBA), Ba. $<$ vaniasampa@yahoo.com.br>

2 Programa de Pós-Graduação em Saúde Coletiva, ISC/UFBA. <nunesm@ufba.br> 


\section{Int rodução}

Em conformidade com as responsabilidades e ações estratégicas prioritárias da atenção básica, a Educação em Saúde figura entre as atribuições de todos os profissionais que integram a equipe de Saúde da Família (Brasil, 2001; 1997). Além dos contextos convencionais de desenvolvimento da ação educativa, como os grupos educativos organizados segundo necessidades de saúde ou patologias específicas, espera-se que o contato cotidiano com os usuários e a comunidade possa ser reconhecido pelos profissionais como uma situação oportuna para o desenvolvimento desta ação.

Estudos empíricos - que abordam as concepções e práticas de Educação em Saúde entre profissionais de centros de saúde convencionais (Machado, 1997; Pereira, 1993) e de equipes de Saúde da Família (Noronha et al., 2004; Alves \& Franco, 2003; Moura \& Rodrigues, 2003; Franco, 2002; Moura \& Souza, 2002) - demonstram a reduzida freqüência com que as ações educativas têm sido desenvolvidas no âmbito desses serviços, particularmente as atividades coletivas. Um ponto de convergência entre esses estudos refere-se à predominância das práticas de Educação em Saúde orientadas pelo modelo hegemônico. De acordo com este modelo, uma relação assimétrica e autoritária é estabelecida entre profissionais e usuários. Estes são considerados carentes de informação em saúde ou portadores de saberes equivocados, razão pela qual os profissionais, orientados pelo conhecimento técnico-científico com status de verdade, transmitem, para aqueles, conteúdos sobre comportamentos e hábitos para uma vida saudável (Alves, 2005; 2004). Este modelo de prática educativa contrasta com a possibilidade de construção compartilhada de conhecimentos sobre o processo saúde-doença-cuidado, mediante uma relação dialógica (Freire, 2003; 2002), e o desenvolvimento da autonomia dos usuários. Ademais, a prescrição de formas de cuidado e atenção à saúde configura uma ação impermeável às dimensões psicossociais e culturais das concepções de saúde, doença e cuidado (Alves, 2005).

Outro ponto de convergência entre os estudos referidos diz respeito à indicação que fazem os profissionais quanto à natureza da consulta como um contexto de Educação em Saúde. A despeito deste reconhecimento, nos estudos revisados, a consulta médica ainda não havia sido analisada como um espaço educativo. Em razão desta lacuna identificada, o presente estudo elegeu a consulta médica como unidade de análise, assumindo como objetivo identificar e caracterizar ações de Educação em Saúde ao longo dessas consultas no contexto do Programa Saúde da Família (PSF).

Dentre as ações cotidianas da equipe de Saúde da Família, o estudo focalizou a atenção no paciente hipertenso. De acordo com as recomendações do PSF, esta atenção deve ser iniciada pela busca ativa de casos na comunidade, seja mediante visitas domiciliares ou rotina de aferição da pressão arterial de usuários. A rotina de atenção a esses pacientes prevê tanto o acompanhamento ambulatorial e domiciliar quanto a assistência farmacêutica e a Educação em Saúde (Brasil, 2001).

Segundo relatório da Organização Mundial de Saúde (OMS, 2003), o cuidado às condições crônicas tem se constituído um importante desafio aos sistemas de saúde. Dentre as propostas inovadoras de cuidado, discute- 
${ }^{3}$ Este estudo foi realizado a partir de dados secundários produzidos pelo projeto de pesquisa "A relação médicopaciente no Programa Saúde da Família: uma pesquisa-ação com as equipes de saúde da família do Ceará e da Bahia", desenvolvido sob financiamento do CNPq. O projeto do presente estudo foi submetido ao Comitê de Ética em Pesquisa do Instituto de Saúde Coletiva (ISC/UFBA), sendo por este aprovado. se a reorientação do modelo assistencial. A relevância das ações educativas em saúde, em todas as interações estabelecidas entre os profissionais e os usuários, é realçada, reconhecendo-se a centralidade que o paciente e sua família devem ocupar na definição das estratégias de cuidado. Nesta perspectiva, a presente análise da atenção médica ao paciente hipertenso enfoca as interações e os processos comunicacionais estabelecidos entre o profissional médico e o paciente no âmbito da consulta.

\section{Metodologia}

O estudo ${ }^{2}$ foi orientado pelos princípios da Etnometodologia (Coulon, 1995), sendo a consulta compreendida como um encontro intersubjetivo entre médico e paciente. Nesta direção, privilegiou-se uma abordagem metodológica que contemplasse a compreensão da ação educativa no seu contexto de produção, salientando-se, deste modo, na análise das consultas, as interações e os processos comunicacionais estabelecidos entre os sujeitos participantes.

O corpus de análise foi constituído pelas transcrições literais de cinqüenta consultas de pacientes hipertensos, conduzidas por dez médicos atuantes em três municípios do Estado da Bahia: um da região do semiárido, outro da região litorânea e, o terceiro, da região metropolitana. A observação e o registro das consultas em áudio realizaram-se mediante consentimento informado de médicos e pacientes. A definição sobre o número de consultas a ser analisado por profissional levou em consideração o objetivo de aproximação com a rotina do médico na atenção ao paciente hipertenso. Assim, cada profissional teve, em média, cinco consultas analisadas.

A maioria das consultas foi conduzida por profissionais do município do semi-árido ( $80 \%)$, que, na ocasião da coleta de dados, tinha como característica proeminente a constituição de uma rede de serviços de saúde integrada, favorecendo o acesso à média complexidade; e uma assistência farmacêutica descentralizada, em que a medicação prescrita era entregue pelo próprio médico durante a consulta - circunstância esta que permitia ao profissional explicar mais detidamente sobre a sua posologia. Em consultas a pacientes analfabetos, esses profissionais podiam recorrer - e, freqüentemente, assim o faziam - às características da medicação para distingui-las, a exemplo da cor da embalagem, formato ou cor dos comprimidos. Nos municípios litorâneo e metropolitano, nos quais observaram-se, respectivamente, $8 \%$ e $12 \%$ das consultas analisadas, as realidades dos sistemas de saúde local eram muito semelhantes. A referência e contra-referência não eram asseguradas em virtude da desarticulação entre os serviços, e a assistência farmacêutica era insuficiente. No município litorâneo, na ocasião de observação das consultas, a farmácia municipal encontrava-se fechada e a distribuição de medicamentos temporariamente suspensa; no município metropolitano, vários medicamentos estavam em falta. Estas particularidades dos contextos municipais repercutem na atenção ao paciente hipertenso e no desenvolvimento da ação educativa ao longo da consulta médica.

A fase de constituição do corpus foi seguida por outras duas fases 
consecutivas e complementares: a análise descritiva da estrutura das consultas e a análise interpretativa segundo categorias empíricas. A descrição da estrutura das consultas possibilitou uma primeira sistematização dos dados, descrevendo-se a interação entre o médico e o paciente, bem como as ações desenvolvidas ao longo dos momentos da consulta que, previamente, foram definidos como: a) anamnese e investigação do problema de saúde; b) realização do exame físico; c) definição do diagnóstico, com esclarecimento do problema de saúde; d) definição do projeto terapêutico e de acompanhamento; e) ação educativa em saúde.

Por meio da análise descritiva, pretendeu-se compreender o modelo de atenção característico nas consultas. A não-assimilação de ações educativas na consulta foi interpretada como um fenômeno característico do predomínio do reducionismo do modelo biomédico, com ênfase na medicalização e remissão de sintomas. Pressupondo-se que nem toda consulta apresentaria o desenvolvimento de ações educativas, a análise descritiva também teve o objetivo de tornar compreensível que fatores ou circunstâncias favoreceriam ou dificultariam o desenvolvimento destas ações na consulta médica do PSF.

Mediante uma interface entre os princípios do PSF, o campo da antropologia médica e o campo da educação, foram definidas, para o estudo, as seguintes categorias analíticas: integralidade da consulta, modelos explicativos e ação educativa. Estas, por sua vez, foram operacionalizadas mediante categorias empíricas correspondentes: a) condução da consulta; b) narrativa do paciente/ família sobre o problema de saúde e práticas de cuidado familiares; c) narrativa do médico sobre o problema de saúde e definição do projeto terapêutico; d) processos comunicacionais sobre o cuidado e a atenção à saúde.

Esta fase analítica, em complementaridade à anterior, buscou apreender as racionalidades orientadoras da atenção médica, salientando os principais temas abordados e assimilados à compreensão do processo saúde-doençacuidado dos pacientes. A integralidade da consulta estaria expressa numa abordagem médica que contemplasse as necessidades de saúde e os determinantes dos problemas referidos pelos pacientes (Camargo Júnior, 2003). Neste estudo, partiu-se do pressuposto de que a integralidade da consulta constituiria uma condição favorável à assimilação da ação educativa.

Outro objetivo dessa fase de análise foi a descrição e a interpretação do processo comunicacional e dos modelos explicativos de médicos e pacientes. Modelos explicativos consistem em explicações a um episódio de doença e ao cuidado terapêutico considerado necessário, reveladas mediante as narrativas dos sujeitos (Kleinman, 1980). Pressupôs-se que o encontro entre diferentes modelos explicativos poderia configurar tanto uma circunstância que dificultasse quanto favorecesse o desenvolvimento de ações educativas. O desdobramento desse encontro foi objeto de análise aprofundada, recorrendo-se, para tanto, a estratégias de análise de conversação e da fala (Myers, 2003; Drew et al., 2001).

Por fim, essa fase teve o objetivo de descrever e caracterizar a ação 


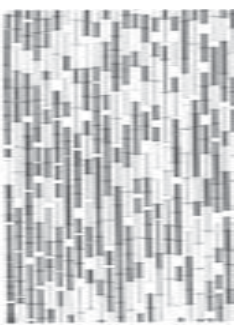

educativa, assim denominada por constituir mais uma ação dentre aquelas realizadas pelo médico ao longo da consulta. Pretendendo-se apreender uma compreensão ampliada de Educação em Saúde, a análise da ação educativa foi realizada mediante a descrição dos processos comunicacionais estabelecidos entre médico e paciente para a abordagem de temas relativos à atenção e ao cuidado com a saúde.

Um limite do presente estudo decorre da natureza do próprio material de análise. As observações das consultas foram pontuais, não sendo possível apreender sobre a continuidade do processo educativo em consultas subseqüentes com o mesmo paciente e em outros momentos interativos. Também não se teve alcance sobre ações educativas realizadas em outros contextos, tais como os grupos educativos e as visitas domiciliares, bem como sobre as conseqüências dessas ações sobre o comportamento dos pacientes e de suas famílias. Todavia, admite-se que a extensão do número de consultas analisadas pode permitir algumas aproximações em razão da diversidade de situações contempladas: consultas nas quais o médico revisa com o paciente o projeto terapêutico definido em consulta anterior e investiga se o paciente vem seguindo devidamente as recomendações recebidas; consultas de pacientes que freqüentam grupos educativos; consultas nas quais os pacientes declaram não-adesão às recomendações e prescrições médicas, entre outras.

\section{Resultados}

A maioria dos pacientes com hipertensão, assistidos nas consultas analisadas, era do sexo feminino (82\%) e com mais de cincoenta anos de idade (58\%). A relação com a unidade de Saúde da Família caracterizava-se pela continuidade da assistência, sendo que $72 \%$ dos pacientes haviam sido atendidos em ocasião anterior à consulta analisada, seja pelo médico ou outro profissional da equipe de saúde. Entretanto, esta continuidade não representa necessariamente uma estabilidade do vínculo com o médico, visto a rotatividade deste profissional nas equipes.

As consultas analisadas foram motivadas principalmente pela hipertensão (62\%) e a maioria dos pacientes encontrava-se com a pressão arterial elevada (64\%) no momento da consulta. A queixa relativa à hipertensão incluía: observação de sintomas associados à el evação ou "descontrole" da pressão, avaliação do efeito da medicação prescrita pelo médico e efeitos colaterais por esta acarretados.

A maioria dos pacientes ( $80 \%)$ encontravam-se sob a prescrição médica de anti-hipertensivo. Destes, $50 \%$ relataram o uso conforme a prescrição, $18 \%$ afirmaram haver descontinuado o uso por conta própria e $12 \%$ referiram usar a medicação prescrita em desacordo com a orientação médica, freqüentemente reduzindo a sua dosagem. A maior freqüência quanto à descontinuidade do uso da medicação prescrita foi observada entre os pacientes mais jovens, com idade entre 35-40 anos. Dos sete pacientes assistidos, com esta faixa etária, quatro tinham recebido a prescrição de anti-hipertensivo e três não deram continuidade ao seu uso.

A descontinuidade total ou parcial do uso da medicação prescrita, declarada por $30 \%$ dos pacientes nas consultas analisadas, não pode ser 
atribuída exclusivamente à insuficiência da assistência farmacêutica nos municípios. Muitos dos pacientes que declararam esta descontinuidade contavam com um sistema de saúde integrado. Em relação a este dado, é possível interpretar que, em alguns casos, uma forma de resistência ou de exercício de autonomia possa estar sendo enunciada na conduta do paciente. Os elementos que subsidiam esta interpretação poderão ser reunidos nas seções subseqüentes.

\section{A condução da consulta: medicalização e controle da hipertensão} A análise das consultas dos pacientes hipertensos aponta três tendências de sua condução pelos médicos. A primeira se caracteriza pela centralidade da queixa manifestada pelo paciente, dos exames físicos e laboratoriais, e pela ênfase conferida ao uso da medicação e ao controle da pressão arterial. A segunda tendência se distingue pela ampliação da investigação de outros problemas de saúde, com realização de uma anamnese clínica extensa, e abordagem de fatores de risco à saúde. Nesta tendência, a dimensão psicossocial, que diz respeito ao sofrimento do paciente e suas relações afetivas com a família e a participação desta no cuidado, poderá ser suscitada em decorrência do tipo de pergunta formulada pelo médico, sem que, no entanto, seja incorporada à condução da consulta e compreensão da condição de saúde do paciente. A última tendência observada caracterizase principalmente pela abordagem médica centrada no paciente e em sua condição de vida. Sem deixar de atentar para o problema de saúde manifesto, o médico formula questões ao paciente que possibilitam a este a ampliação de sua narrativa e, conseqüentemente, da compreensão do problema.

A primeira tendência é a dominante. A rotina de atenção ao paciente hipertenso, de sete médicos, foi por ela orientada. A segunda tendência foi observada entre dois médicos e apenas um profissional mostrou-se orientar pela terceira das tendências descritas. Entre os profissionais, a rotina de atenção ao paciente hipertenso não apresentou distinção quanto ao fato de se tratar de atendimento a um caso novo ou a um paciente já assistido pela equipe de Saúde da Família.

De acordo com a primeira tendência, a consulta pode ser iniciada pela apresentação de resultados de exames laboratoriais, pela queixa do paciente ou pela verificação do médico quanto ao uso da medicação e controle da pressão arterial. Os resultados de exames irão subsidiar a construção da narrativa do médico sobre o problema. A estes, soma-se a realização do exame físico durante a consulta que, na maioria das vezes, consiste em uma verificação do estado geral do paciente e na aferição de sua pressão arterial. Esta, porém, pode ser aferida antes da consulta por outro profissional da equipe de saúde.

A constatação de pressão arterial elevada é imediatamente seguida pela indagação do médico a respeito do uso da medicação prescrita. Nessas consultas, a dimensão psicossocial do processo saúde-doença pode emergir, na maioria das vezes, espontaneamente, mas a escuta da questão pelo médico pode ser comprometida pela ênfase conferida à medicação ou ao esclar ecimento diagnóstico. Em uma consulta com um senhor de 74 anos,

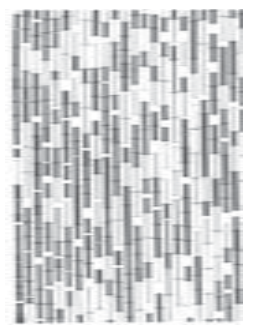


a médica questiona sobre algum aborrecimento, ela mesmo antecipando uma resposta negativa. O paciente refere que sentiu uma "raiva" naquela manhã. As possíveis razões dessa "raiva", entretanto, não são investigadas pela profissional, embora acabe atribuindo a alteração da pressão a essa condição. Mais importante do que uma escuta interessada sobre a "raiva" experimentada pelo paciente naquela manhã, parece ser a conclusão diagnóstica:

M: Mas aconteceu alguma coisa, teve algum aborrecimento? Não.

$\mathrm{P}$ : Teve, doutora, cala a boca, que eu tive uma raiva tão grande, doutora.

M: Então foi por isso!

Na segunda tendência de condução da consulta com o paciente hipertenso, uma anamnese extensa é realizada pelo médico, o que repercute na duração da consulta, em geral mais longa que as referentes à tendência anterior. A anamnese inclui investigação de outros sintomas não relatados inicialmente pelo paciente: de fatores de risco individuais, como tabagismo e consumo de bebida alcoólica, de antecedentes mórbidos familiares, e quanto à realização de exames preventivos. As perguntas formuladas pelo médico favorecem uma narrativa do paciente que não se restringe à descrição dos sintomas observados, e a emersão da dimensão psicossocial. Entretanto, a abordagem a esta dimensão mostra-se superficial, sem sua incorporação à compreensão da condição de saúde do paciente.

Uma condução diferenciada da consulta foi observada em relação a um profissional, cuja abordagem médica leva em conta a condição de vida do paciente. Mediante uma escuta interessada e por meio da formulação de perguntas - estratégia de problematização -, o médico estimula a narrativa de seus pacientes e a ampliação de sua compreensão quanto ao problema narrado. Assim, o processo saúde-doença pode ser remetido à condição de vida, com ponderação de estratégias de enfrentamento pelo paciente. Reconhecido como sujeito, nessa relação, o paciente pode exercer uma ação transformadora da realidade que incide sobre sua saúde.

A descrição de uma consulta desse profissional ilustra as considerações a respeito dessa terceira tendência identificada de condução das consultas. Uma senhora de 72 anos, obesa, refere que estava sem usar o antihipertensivo há alguns dias. A abordagem do médico se distingue daquela observada entre os outros profissionais; em vez de repreender a paciente pela descontinuidade do uso da medicação e repetir que ela não deveria ficar sem usá-la sequer um dia, o médico indaga "por que, o que aconteceu?". A senhora explica que a farmácia municipal encontrava-se fechada e a distribuição de medicamentos suspensa. A situação da paciente e de sua família é de muita pobreza e ela vive o dilema de ter que optar entre comprar a medicação, que compreende que precisa usar continuadamente, e a alimentação. A decisão foi pela subsistência e os remédios não puderam ser adquiridos.

A história familiar da paciente e o relato de sua condição socioeconômica são ouvidos pelo médico e assimilados à abordagem de seu problema de 
saúde. A narrativa da paciente é extensa, estimulada pela formulação de perguntas pelo médico, e refere o desemprego na família, a ajuda aos filhos desempregados, os cuidados com os netos. A despeito de toda adversidade, o médico não deixa de acreditar na capacidade criativa da paciente e na possibilidade de transformação dessa realidade. A situação da suspensão da distribuição de medicamentos da atenção básica era um problema reconhecido por médico e paciente. A previsão era de que a farmácia municipal voltaria a funcionar dentro de um mês. A pressão da senhora já estava elevada em razão da descontinuidade do uso da medicação, razão pela qual o médico não deixa de indagar: "como fazer para comprar o remédio?". A pergunta traz à tona o projeto da paciente de fazer uma "puxadinha" na frente da casa para que ela e o marido possam vender "bananinha, farinhinha...". Este projeto, além de viabilizar a aquisição de medicamentos, propiciaria uma melhora da condição de vida de toda a família.

A postura desse profissional diante de seus pacientes, ao conduzir a consulta, distingue-se não apenas pela escuta compromissada, a assimilação da dimensão psicossocial e da condição concreta de vida deles, mas também pela maneira como se despede dos pacientess: "Tchau, felicidades pra senhora". O compromisso do médico se reflete no estreitamento do vínculo, sendo a consulta subseqüente agendada não para apresentar resultado de exames ou verificar o controle da pressão, mas para uma conversa: "Quarta-feira a gente conversa de novo aqui no consultório?". O enfoque da atenção não está na doença, mas no sujeito portador de uma biografia. Ao longo das consultas desse profissional, delineia-se a construção compartilhada de um projeto futuro de felicidade (Ayres, 2001), o que ultrapassa a mera remissão dos sintomas mediante uso continuado de medicamentos.

Entre as três tendências de condução das consultas com o paciente hipertenso, verifica-se a predominância de uma abordagem orientada pelo reducionismo do modelo biomédico. A ênfase conferida aos sintomas e sua descrição, ao uso da medicação e ao controle da pressão arterial põe em evidência uma atenção médica centrada no indivíduo e na construção do diagnóstico, em detrimento de uma abordagem integradora da história de vida, sofrimentos, anseios e condições concretas de vida dos pacientes.

Estas considerações indicam que a maioria das consultas ao paciente hipertenso analisadas não corresponde a uma atenção integral. Esta, além de socioculturalmente contextualizada, reconheceria, no paciente, um sujeito transformador da realidade e agente co-responsável pelo cuidado com a própria saúde. A identificação de uma tendência contra-hegemônica entre as consultas analisadas aponta, entretanto, a possibilidade de reorientação da prática de saúde dominante.

\section{A narrativa dos pacientes: sujeito em busca de autonomia}

A narrativa dos pacientes nas consultas analisadas limita-se, na maioria das vezes, à descrição dos sintomas observados, muito pouco revelando de seus modelos explicativos. A narrativa estimulada pelos médicos é aquela que oferecerá a eles maior detalhamento para o esclarecimento do diagnóstico 
segundo as categorias nosológicas definidas pela biomedicina e informações relativas a fatores de risco à saúde. Nas consultas de avaliação do projeto terapêutico, a narrativa do paciente pode ser inibida pela apresentação de resultados de exames laboratoriais ou pela consulta ao prontuário e revisão de procedimentos e prescrições anteriores. Narrativas sobre as relações familiares e as condições concretas de vida são comumente inibidas ou interrompidas pelo médico.

Apenas nas consultas conduzidas pelo profissional cuja abordagem foi anteriormente distinguida, pôde-se verificar uma estimulação da narrativa dos pacientes, de modo que a descrição dos sintomas pudesse ser contextualizada. Nessas consultas, a estratégia de problematização conferiu uma transcendência da compreensão do problema de saúde e a sua ressignificação repercutiu na elaboração de alternativas de enfrentamento do problema experimentado pelos pacientes.

Embora uma narrativa aprofundada do problema de saúde e sua contextualização na experiência de vida do paciente possam conferir maior integralidade à atenção médica, a narrativa da maioria dos pacientes assistidos nas consultas analisadas caracteriza-se pela sua superficialidade. Ainda assim, a análise dessas narrativas suscita algumas questões relativas à construção da experiência da doença pelo paciente e sua repercussão para o cuidado em saúde.

A cronicidade da hipertensão pode não ser incorporada à experiência da doença de alguns pacientes, cuja observação dos sintomas apresenta-se associada a uma noção de temporalidade ou sazonalidade. Esta concepção produz conseqüências quanto ao uso da medicação prescrita, a qual pode ser descontinuada em virtude da observação de remissão dos sintomas. A narrativa a seguir explicita esta concepção. Trata-se de uma senhora de 54 anos, cuja queixa é de que o coração agita nos dias quentes e que se sente bem nos demais dias. A esta compreensão da paciente sobre o seu processo saúde-doença, nenhuma consideração esclarecedora foi tecida pelo médico:

M: Sim, a senhora tá sentindo o quê?

P: Eu tô sentindo uma... aqui no joelho e mais um problema que quando o dia tá quente eu não tenho ânimo pra fazer nada, sabe?, até pra limpar a casa, eu preciso limpar aos poucos, descansar, e já aconteceu também eu cair duas ou três vezes. Quando o dia tá quente, agora o dia tando frio eu tô bem. Não posso fazer nada nas carreiras...

$\mathrm{M}$ : Hum, hum.

P: Se eu correr, o meu coração agita...

$M$ : Se corre?

P: É, eu não posso fazer nada... correr, não posso viajar com pressa, tem que ser tudo devagar.

M: E quando tá frio, se a senhora corre, o coração não agita não?

P: Não.

$M:$ Não?

P: Só quando está quente. 
A adesão à prescrição médica relaciona-se estreitamente à construção da experiência da doença pelo paciente (Kleinman, 1980). Saber-se hipertenso pode ter como conseqüência o uso contínuo da medicação prescrita. Neste caso, a adesão configura uma livre escolha de acatar as recomendações recebidas dos médicos. Nesta perspectiva, a adesão pode ser compreendida como uma expressão do exercício de autonomia do paciente no cuidado com a própria saúde.

Entretanto, a autonomia do paciente no cuidado com a saúde pode assumir outras expressões que não a adesão à prescrição médica. A observação de efeitos colaterais do anti-hipertensivo pode levar à descontinuidade total ou parcial do seu consumo, ou, ainda, a sua substituição pelos remédios caseiros. Em ambas as circunstâncias, o paciente poderá ser repreendido pelo médico com a advertência de que não pode ficar sem usar a medicação.

A autonomia do paciente, quando não corresponde à adesão à prescrição médica, comumente não é reconhecida e valorizada pelo médico. Sem uma disposição do profissional para a compreensão das práticas populares de cuidado e a abertura de um espaço para negociação, o que se observa é uma ação antidialógica e culturalmente invasiva (Freire, 2003), na qual as práticas populares são marginalizadas.

Ainda em relação à autonomia do paciente hipertenso, identifica-se, em muitas das consultas, um sujeito em busca de conhecimento sobre a sua condição de saúde, conhecimento este que poderá ser traduzido na conquista de uma maior independência no cuidado. Esta disposição do paciente, que Freire (2003) apreciaria como expressão de sua vocação ontológica de ser mais, ser sujeito, repercute na relação médico-paciente. Os médicos são levados a compartilhar mais informações com os pacientes mais questionadores, o que não se processaria espontaneamente, como evidenciado naquelas consultas nas quais o paciente assume uma postura mais passiva.

Entretanto, a disposição dos pacientes em saber sobre sua condição de saúde pode não ser aproveitada pelo médico para o desenvolvimento da autonomia do paciente. Nessa situação, o profissional não responde às indagações ou dúvidas a ele dirigidas, ou oferece uma resposta superficial e estritamente biomédica. Em algumas interações, uma relação de poder é claramente instituída pelo profissional, sustentada no monopólio do conhecimento biomédico. Esta circunstância pode implicar restrições no oferecimento de esclarecimentos, requisitados pelo paciente, relativos à sua saúde.

$\mathrm{Na}$ consulta de uma senhora de setenta anos, a informação sobre o resultado do exame de colesterol apenas foi obtida mediante sua perseverança. Após entregar os resultados de exames laboratoriais e esperar sua apreciação pela médica, a paciente é comunicada de que os exames "estão jóia". A senhora tem um interesse particular pelo exame de colesterol. A médica, mesmo diante do interesse manifesto pela paciente, afirma-Ihe que "ainda não cheguei lá. Tô vendo aqui anemia, não tem anemia, não tem infecção, o exame da tireóide que eu pedi também foi bom. E a pressão?". Desta maneira, a profissional demarca o seu controle 
na condução da consulta. Quando finalmente informa sobre o exame de colesterol, restringe-se à afirmação "tá beleza!". A senhora, no ápice de sua busca de conhecimento sobre sua condição de saúde, indaga "quanto está?", obtendo como resposta "180". Diante desta resposta, a senhora ainda precisa conferir se "180" significa um valor dentro da normalidade para, finalmente, comemorar o exercício de autonomia no cuidado e atenção com a saúde. Em exame anterior, o colesterol estava bastante elevado, em torno de $340 \mathrm{mg} / \mathrm{dl}$, e desde então, ela vem usando a "brijela" [berinjela] e avalia, mediante o exame recente, a eficácia do cuidado assumido por ela.

A respeito da busca de conhecimento sobre a condição de saúde-doença e da autonomia do paciente, é importante ressaltar a sua independência em relação à faixa etária ou outra característica do paciente. A análise das consultas evidencia que mesmo pacientes idosos são capazes de atender à vocação de ser sujeito, agente co-responsável pelo cuidado com a própria saúde. Esta observação contraria considerações de alguns estudiosos da relação médico-paciente, cuja afirmação é de que pacientes com um determinado perfil - idosos, pacientes com baixa renda, com ocupações profissionais pouco qualificadas, baixa escolaridade - tendem a preferir uma relação paternalista com seus médicos, assumindo perante estes uma postura passiva e dependente (Roter \& Hall, 1993).

\section{A narrativa dos médicos: monopolizando o conhecimento sobre a saúde, a doença e o cuidado}

A narrativa dos médicos, nas consultas com pacientes hipertensos analisadas, caracteriza-se predominantemente como prescritiva. A ênfase desta narrativa recai sobre o uso da medicação, sendo a ação educativa secundária e superficial. O modelo explicativo do médico freqüentemente não é exposto ao paciente. Ao contrário, a comunicação quanto à pressão arterial verificada durante a consulta ou a respeito dos resultados de exames não são esclarecedoras. Expressões evasivas ou emprego de diminutivos caracterizam os enunciados médicos: "um pouquinho alta",

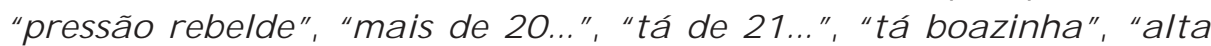
para a pessoa", "pressão altinha", "tá boa", "está ótima", "tá muito alta", "não é normal não". Quanto a estas expressões, depreende-se que elas não favorecem uma compreensão do paciente sobre a sua real condição de saúde.

Uma consideração semel hante ao enunciado da pressão arterial pode ser feita em relação à medicação. Esta nem sempre é referida pelo nome, com os médicos fazendo menção a suas características visuais, como a cor da embalagem, a cor ou o formato do comprimido, ou mais uma vez empregando ordem de grandeza: "comprimido grandão", "comprimido alvinho" e "remedinho", são alguns exemplos.

Entretanto, a narrativa do médico sobre a hipertensão poderá ser ampliada, com o médico explanando sobre o tema. Esta narrativa pode ser qualificada de dissertativa (Freire, 2003), visto não haver qualquer participação do paciente na abordagem do tema, sendo sua escuta passiva e silenciosa. Outra característica desta narrativa, verdadeiro depósito de 
conteúdo biomédico, é a não-verificação da compreensão do paciente, com expressão de sua concordância ou de dúvidas. O objetivo da narrativa médica apresenta-se bem definido: conquistar a adesão do paciente à prescrição.

A narrativa do médico freqüentemente acentua o risco, o perigo, sugerindo ao paciente ser a hipertensão uma ameaça constante, o que justifica, por outro lado, a imprescindibilidade da incessante vigilância. Em uma de suas consultas, um profissional ressalta a importância do cuidado com a seguinte consideração: "Pressão a gente fica... tem que ter um cuidado danado, né? Pressão é um negócio traiçoeiro". Outro profissional retrata a ausência de sintomas da hipertensão como um perigo, assinalando a importância da aferição periódica. O controle da pressão arterial, mediante uso contínuo da medicação e aferição periódica na unidade de saúde, é a tônica da narrativa médica.

O projeto terapêutico é definido pelo médico sem participação ou negociação com o paciente. Neste sentido, a narrativa deste não será levada em consideração no momento da prescrição. Assim, por exemplo, na consulta da paciente que narra que o coração agita nos dias quentes e que se sente bem nos dias frios, a prescrição é de uso diário e vitalício. A paciente, cuja história pregressa é de descontinuidade de uso da medicação, não consegue completar o que seria possivelmente uma expressão de sua concepção de cuidado compatível com a sua noção de temporalidade da hipertensão:

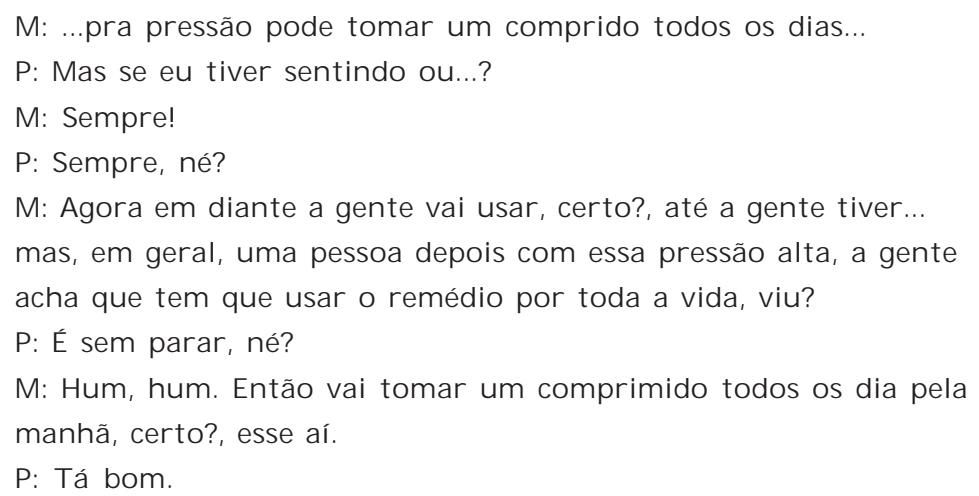

Nesta interação, compreende-se que, no "tá bom", encerra-se a possibilidade de uma ação dialógica, centrada na narrativa do paciente. A não-escuta também obstaculiza a negociação, sendo, muitas vezes, a prescrição reiterada pelo médico sem que seja considerada a relação estabelecida pelo paciente com a medicação. No lugar da negociação, o que se verifica é uma tentativa de convencimento pela transmissão de informação biomédica, na qual são acentuados os danos à saúde conseqüentes da não-adesão à prescrição.

O projeto terapêutico definido pelo médico é avaliado por este mediante acompanhamento do resultado terapêutico almejado: o controle da pressão arterial. Assim sendo, a substituição da medicação ou o aumento de sua dosagem são procedimentos previstos e mesmo anunciados aos pacientes como parte deste projeto. Destaca-se, nesta prática, a busca do "remédio que 
dê certo". Como se pode observar na interação a seguir, esta busca se sobrepõe, muitas vezes, à ação educativa em saúde:

\footnotetext{
M: Ela tá de vinte e um por doze, viu?, a pressão, dona A. Sua pressão é muito alta.

P: Tem que controlar muito o negócio de sal, né?

M: Hum, hum. Tem que ver o sal, tem que ver isso aqui, tem que ver também a medicação. Toda vez... tem pressão também que são mais rebeldes, assim, pressão que é mais rebelde pra controlar. Mas o... agora, a gente vai aumentar a quantidade, observar o sal e se não... a gente vai trocar o remédio, viu? Tem que procurar o remédio que dê certo.
}

Sendo a narrativa do médico tão enfática quanto à doença e sua medicalização, pode-se compreender porque a ação educativa, nessas consultas com pacientes hipertensos, apresenta-se tão secundária. Hierarquicamente, o projeto terapêutico preconiza o uso da medicação em conformidade com a prescrição, a aferição periódica da pressão arterial na unidade de saúde, para acompanhamento do efeito terapêutico da medicação e, por último e marginalmente, a ação educativa em saúde.

\section{A ação educativa: prescrevendo formas de cuidado com a saúde} Quanto ao desenvolvimento da ação educativa, três circunstâncias são observadas: 1 consultas enfaticamente curativas, nas quais a narrativa do médico sobre a atenção e o cuidado à saúde se restringe à reiteração prescritiva quanto ao uso contínuo e apropriado da medicação; 2 consultas em que a ação educativa é assimilada de forma secundária no projeto terapêutico, com a abordagem de outros cuidados necessários à saúde, particularmente a redução dos fatores de risco à hipertensão; 3 consultas em que o projeto terapêutico se caracteriza pelo equilíbrio entre a medicalização, o controle da pressão arterial e o desenvolvimento da ação educativa. Dentre estas três circunstâncias, a segunda é preponderante. Dentre as cinqüenta consultas analisadas, em apenas três observa-se um certo equilíbrio no projeto terapêutico. Trata-se de consultas nas quais a extensão da narrativa médica confere uma importância equilibrada às recomendações feitas nas três direções. Entretanto, o equilíbrio observado não caracteriza uma rotina do profissional na atenção ao paciente hipertenso.

Nas consultas em que a atenção médica enfatiza exclusivamente a medicalização, as ações de cuidado do paciente com sua própria saúde expressão de sua autonomia - podem não ser reconhecidas e potencializadas pelo médico. A consulta de uma senhora de 68 anos é ilustrativa desta consideração. A médica inicia a consulta investigando o uso do anti-hipertensivo e acentua que "tem que tomar o remédio". A pressão arterial está elevada na ocasião do atendimento, a paciente afirma que sua pressão é "descontrolada". Esta observação da paciente é seguida pelo comentário médico de que "vai ter que obter o controle dela". Imediatamente a este comentário, a paciente anuncia que vem seguindo 
uma dieta hipossódica e reduzindo o consumo de gordura: “Não como... não como mais muita gordura, não como sal...", o que parece indicar uma concepção de cuidado da paciente que vai além do uso da medicação. Entretanto, esta ação de cuidado referida não é estimulada pela médica que conclui: "eu vou aumentar esse remédio pra senhora".

Entretanto, as ações de cuidado do paciente hipertenso, quando coerentes com a prescrição médica e orientadas para a redução de riscos individuais, são, em geral, valorizadas e incentivadas pelos profissionais. Um senhor de 62 anos, que afirma ser uma pessoa sadia, refere autonomia na atenção e cuidado com a saúde e adesão às prescrições médicas. A partir da suspeita de que a pressão arterial estava elevada, dirigiu-se a uma farmácia para verificá-la e, depois, a um serviço de saúde, onde o profissional que o atendeu recomendou que comesse sem sal, deixasse de tomar café e fumar. O senhor afirma ao médico que, há uma semana, vinha seguindo à risca tais recomendações, sem, contudo, deixar de assinalar o desafio de assumir estas restrições. O médico, nessa oportunidade, o encoraja a dar continuidade aos "novos hábitos".

A investigação de fatores de risco apara a hipertensão - tabagismo, consumo de bebida alcoólica, sedentarismo, dieta, antecedentes de cardiopatias na família - pode integrar a anamnese clínica. Entretanto, a relação entre estes fatores de risco e a hipertensão não é necessariamente explicitada pelos profissionais aos pacientes, principalmente quando a resposta destes é negativa. A anamnese clínica oferece subsídios para a definição diagnóstica, não constituindo um momento da consulta aproveitado para a ação educativa em saúde.

Dentre os fatores de risco para a hipertensão, a alimentação destaca-se como o mais referido pelos profissionais. Contudo, a abordagem quanto à dieta do paciente hipertenso restringe-se à recomendação de redução do consumo de sal e gorduras. A orientação geral é de que "tem que comer bem pouco sal" ou ainda "não tocar em sal". Contudo, sem levar em consideração as condições concretas de vida dos pacientes, estas recomendações quanto à dieta caracterizam-se, essencialmente, como prescritivas, implicando, muitas vezes, a enumeração de alimentos que deverão ser incluídos ou excluídos da dieta do paciente.

A observação da dieta pode ser incorporada ao discurso de alguns pacientes enquanto ação de cuidado necessária. Nesta direção, uma senhora de 63 anos, que antes era atendida em outro serviço de saúde, solicita ao médico de Saúde da Família que oriente a ela quanto à "comida", esclarecendo que o profissional do outro serviço havia apenas prescrito medicamentos:

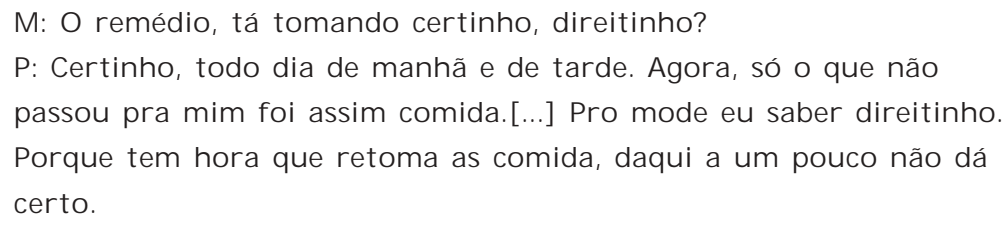

No que diz respeito à dieta, a orientação médica freqüentemente não parte da realidade do paciente. Na consulta de uma senhora de quarenta anos, a médica recomenda a adoção de uma dieta livre de "comida gorda, comida pesada, 
comida muito forte", sem levar em consideração os possíveis sentidos destes alimentos para a paciente, sentidos estes socioculturalmente construídos e compartilhados na comunidade assistida pela equipe de Saúde da Família:

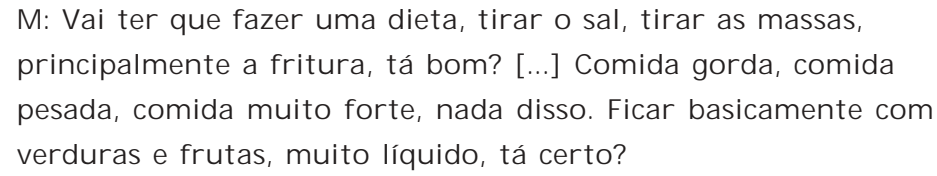

A relação entre a alimentação e as concepções de saúde, doença e cuidado entre indivíduos das classes populares tem sido descrita em estudos etnográficos (Ferreira, 1998; Montero, 1985; Loyola, 1984). De acordo com esses estudos, a concepção de saúde entre populares apresenta-se freqüentemente associada à noção de força e resistência física. Em conformidade com esta concepção, o enfrentamento da doença implica a restituição da força ao corpo, principalmente por meio da alimentação e do repouso. A qualidade da alimentação, nas classes populares, pode ser reconhecida como fator de proteção, e alimentos classificados como "fortes", "pesados" e "quentes" podem ser valorizados como fonte de sustentação e força (Loyola, 1984, p. 153). Contudo, as consultas médicas analisadas no presente estudo mostram-se impermeáveis à dimensão sociocultural das concepções de saúde, doença e práticas de cuidado entre pacientes com hipertensão arterial.

Além da dieta, as recomendações médicas contemplam, ainda, realização de caminhadas e redução do peso, de consumo de bebida alcoólica e de cigarro, sempre numa perspectiva prescritiva. Evidencia-se que a ação educativa desenvolvida nessas consultas tem como objetivo a redução de riscos individuais. Em coerência com esta orientação, fatores de risco relacionados à condição de vida deixam de ser abordados. Trata-se do modelo hegemônico de Educação em Saúde (Alves, 2005; 2004). Todavia, o alcance deste modelo é percebido como limitado em uma auto-avaliação feita por uma médica, que, após atender uma série de pacientes que sucessivamente Ihe declaram a não-adesão à prescrição do anti-hipertensivo e da dieta hipossódica, expressa sua frustração e descontentamento: “É, minhas palestras, consultas não tão adiantando nada, rapaz, vou me embora!".

\section{Consider ações finais}

O modelo hegemônico de Educação em Saúde mantém-se coerente com a orientação estritamente biomédica da atenção ao paciente hipertenso. 0 enfoque na doença e no indivíduo são alicerces da ação educativa que objetiva, mediante a prescrição de hábitos e condutas, a redução de fatores de risco individuais e prevenção de complicações à saúde derivadas da hipertensão.

Entretanto, dentre as consultas analisadas, identifica-se uma abordagem que se distingue do modelo de Educação em Saúde hegemônico. A condução das consultas por um dos profissionais privilegia o desenvolvimento da autonomia dos pacientes, ampliando a sua compreensão do problema e reflexão quanto a uma intervenção sobre a realidade que o contextualiza e 
determina. Esta é uma abordagem que assume, como ponto de partida, o indivíduo, não a sua doença. O objetivo final da ação médica não está na remissão dos sintomas, mas na promoção do cuidado com a saúde e outras dimensões da vida, a exemplo da geração de renda. Evidentemente que esse profissional assume uma postura que propicia uma relação dialógica, ao acreditar no potencial criativo de seus pacientes-sujeitos.

A exceção, por vezes, merece mais destaque que a norma, especialmente quando se tem como pano de fundo de investigação uma proposta de reorientação de práticas de saúde, como é o caso da estratégia do PSF. A força da exceção identificada na presente análise reside justamente na afirmação de que, por maior que seja o desafio de ressignificar a relação com o outro e o cuidado em saúde, este não constitui uma transformação da ordem do impossível. Neste sentido, pode-se, ainda, declarar que, na exceção, se revitaliza a esperança.

\section{Referências}

ALVES, V. S. Educação em Saúde e constituição de sujeitos: desafios ao cuidado no Programa Saúde da Família. 2004. Dissertação (Mestrado) - Instituto de Saúde Coletiva, Universidade Federal da Bahia, Salvador.

ALVES, V. S. Um modelo de educação em saúde para o Programa Saúde da Família: pela integralidade da atenção e reorientação do modelo assistencial. Interface - Comunic., Saúde, Educ., v. 9, n. 16, p.39-52, 2005.

ALVES, V. S.; FRANCO, A. L. S. Estratégias comunicacionais do médico de Saúde da Família para Educação em Saúde no contexto clínico. In: CONGRESSO BRASILEIRO DE SAÚDE COLETIVA, 7., 2003, Brasília. Ciênc. Saúde Colet., v.8, supl.1, p.144, 2003.

AYRES, J. R. C. M. Sujeito, intersubjetividade e práticas de saúde. Ciênc. Saúde Colet., v. 6, n 1, p.63-72, 2001.

BRASIL. Ministério da Saúde. Saúde da Família: uma estratégia para a reorientação do modelo assistencial. Brasília: Ministério da Saúde, 1997.

BRASIL. Ministério da Saúde. Guia prático do Programa Saúde da Família. Brasília: Ministério da Saúde, 2001.

CAMARGO JÚNIOR, K. R. Um ensaio sobre a (in)definição de integralidade. In: PINHEIRO, R.; MATTOS, R. A. (Org.). Construção da integralidade: cotidiano, saberes e práticas em saúde. Rio de Janeiro: UERJ, IMS: ABRASCO, 2003. p.35-44.

COULON, A. Etnometodologia. Petrópolis: Vozes, 1995.

DREW, P.; CHATWIN, J.; COLLINS, S. A conversation analysis: a method for research into interactions between patients and health-care professionals. Health Expect., v.4, p.58-70, 2001.

FERREIRA, J. Cuidados do corpo em vila de classe popular. In: DUARTE, L. F. D.; LEAL, O. F. (Org.) Doença, sofrimento, perturbação: perspectivas etnográficas. Rio de Janeiro: Fiocruz, 1998. p.4956.

FRANCO, A. L. S. A relação médico-paciente no contexto do Programa de Saúde da Família: um estudo observacional em três municípios baianos. 2002. Tese (Doutorado) - Instituto de Saúde Coletiva, Universidade Federal da Bahia, Salvador.

FREIRE, P. Educação como prática da liberdade. 26.ed. Rio de Janeiro: Paz e Terra, 2002. 
FREIRE, P. Pedagogia do oprimido. 37.ed. Rio de Janeiro: Paz e Terra, 2003.

KLEINMAN, A. Orientations 3: core clinical functions and explanatory models. In: KLEINMAN, A. Patients and healers in the context of culture: an exploration of the borderland between Anthropology, Medicine, and Psychiatry. Berkeley: University of California Press, 1980. p.71-118.

LOYOLA, M. A. Médicos e curandeiros: conflito social e saúde. São Paulo: DIFEL, 1984.

MACHADO, M. L. T. Educação e saúde: concepções teóricas e práticas profissionais em um serviço público de saúde. 1997. Dissertação (Mestrado) - Centro de Educação e Ciências Humanas, Universidade Federal de São Carlos, São Carlos.

MONTERO, P. Da doença à desordem: a magia na umbanda. Rio de Janeiro: Graal, 1985.

MOURA, E. R. F.; SOUSA, R. A. Educação em saúde reprodutiva: proposta ou realidade do Programa Saúde da Família? Cad. Saúde Pública, v.18, n.6, p.1809-11, 2002.

MOURA, E. R. F.; RODRIGUES, M. S. P. Comunicação e informação em saúde no pré-natal. Interface Comunic., Saúde, Educ., v.7, n.13, p.109-18, 2003.

MYERS, G. Análise da conversação e da fala. In: BAUER, M. W.; GASKELL, G. (Org.) Pesquisa qualitativa com texto, imagem e som: um manual prático. 2.ed. Petrópolis: Vozes, 2003. p.271-92.

NORONHA, C. V.; FRANCO, A. L. S.; GARRIDO, E. N.; ALVES, V. S. Projeto Saúde para todos na

América Latina: identificando as necessidades de capacitação dos profissionais do Programa Saúde da Família. Salvador: UFBA/ISC, 2004.

OMS. Cuidados inovadores para condições crônicas: componentes estruturais de ação: relatório mundial. Brasília: Organização Mundial da Saúde, 2003.

PEREIRA, G. S. O profissional de saúde e a Educação em Saúde: representações de uma prática. 1993. Dissertação (Mestrado) - Escola Nacional de Saúde Pública, Fiocruz, Rio de Janeiro.

ROTER, D. L; HALL, J. A. Models of the doctor-patient relationship. In: ROTER, D. L; HALL, J. A. Doctors talking with patients: patients talking with doctors. Westport CT: Anburn House, 1993. p.21-37.

ALVES, V. S.; NUNES, M. O. Educación en salud en la atención médica al paciente con hipertensión arterial en el programa de salud de la familia. Interface - Comunic., Saúde, Educ., v.10, n.19, p.131-47, jan/jun 2006.

Entre los muchos contextos de desarrollo de la acción educativa en salud, el presente trabajo privilegió la consulta médica. Con el objetivo de identificar y caracterizar estas acciones en la atención médica, se analizaron las transcripciones de cincuenta consultas con pacientes hipertensos realizadas por diez médicos de salud de la familia en tres municipios del estado de Bahía. Los resultados demuestran que la conducción de la consulta enfatiza la medicalización y el control de la hipertensión. La narrativa del paciente es inhibida o interrumpida por la narrativa del médico, y la atención médica se circunscribe a los síntomas individuales, sin aprehender las dimensiones psicosociales y culturales del proceso salud-enfermedad-cuidado. La acción educativa en la mayoría de estas consultas se presenta secundaria y superficial, con recomendaciones prescriptivas. Un abordaje diferenciado fue identificado en uno de los médicos, lo que mostró la posibilidad de una atención médica dialógica e integradora de aspectos biomédicos y socioculturales al cuidado.

PALABRAS CLAVE: educación en salud. relación médico-paciente. programa salud de la familia. hipertensión. 